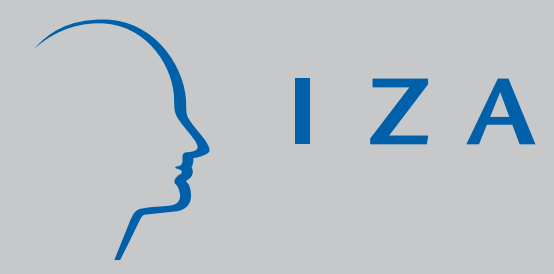

IZADP No. 2396

On the "Adverse Selection" of Organizations

Matthias Kräkel

October 2006 


\title{
On the "Adverse Selection" of Organizations
}

\author{
Matthias Kräkel \\ University of Bonn \\ and IZA Bonn
}

\section{Discussion Paper No. 2396 \\ October 2006}

\author{
IZA \\ P.O. Box 7240 \\ 53072 Bonn \\ Germany \\ Phone: +49-228-3894-0 \\ Fax: +49-228-3894-180 \\ Email: iza@iza.org
}

\begin{abstract}
Any opinions expressed here are those of the author(s) and not those of the institute. Research disseminated by IZA may include views on policy, but the institute itself takes no institutional policy positions.

The Institute for the Study of Labor (IZA) in Bonn is a local and virtual international research center and a place of communication between science, politics and business. IZA is an independent nonprofit company supported by Deutsche Post World Net. The center is associated with the University of Bonn and offers a stimulating research environment through its research networks, research support, and visitors and doctoral programs. IZA engages in (i) original and internationally competitive research in all fields of labor economics, (ii) development of policy concepts, and (iii) dissemination of research results and concepts to the interested public.
\end{abstract}

IZA Discussion Papers often represent preliminary work and are circulated to encourage discussion. Citation of such a paper should account for its provisional character. A revised version may be available directly from the author. 
IZA Discussion Paper No. 2396

October 2006

\section{ABSTRACT \\ On the "Adverse Selection" of Organizations"}

According to New Institutional Economics, two or more individuals will found an organization, if it leads to a benefit compared to market allocation. A natural consequence will then be internal rent seeking. We discuss the interrelation between profits, rent seeking and the foundation of organizations. Typically, we expect that highly profitable firms are always founded but it is not clear whether the same is true for firms with less optimistic prospects. We will show that internal rent seeking may lead to a completely reversed result. The impact of internal rent seeking on overall investment and the implications of firm size and competition on the foundation of organizations are also addressed.

JEL Classification: D2, L2, M2

Keywords: contests, foundation of organizations, internal rent seeking

Corresponding author:

Matthias Kräkel

BWL II

University of Bonn

Adenauerallee 24-42

D-53113 Bonn

Germany

E-mail: m.kraekel@uni-bonn.de

\footnotetext{
* I would like to thank Marion Eberlein, Oliver Gürtler, Judith Przemeck and Dirk Sliwka for helpful comments. Financial support by the Deutsche Forschungsgemeinschaft (DFG), grant KR 2077/2-3 and SFB/Transregio 15 "Governance and the Efficiency of Economic Systems", is gratefully acknowledged.
} 


\section{Introduction}

Following the main idea of New Institutional Economics, market frictions (like transaction costs) or market failures are a necessary condition for the emergence of institutions and organizations (Arrow 1969, 1985; Furubotn and Richter 2005). In such situations, two or more individuals will found an organization if it generates a benefit compared to pure market allocation. This benefit can be referred to as the organization's rent. ${ }^{1}$ However, if internal relations are (at least partly) covered by incomplete contracts, there will be a struggle among the organization members when distributing the rent. This struggle can be characterized as influence activities (e.g. Milgrom 1988, Milgrom and Roberts 1988) or internal rent seeking (e.g. Müller and Wärneryd 2001; Inderst, Müller and Wärneryd 2005, 2006).

In this paper, we will show that such struggle may lead to a situation in which highly profitable firms are not founded due to excessive rent seeking. In contrast, less profitable firms are founded since organization members have only low incentives for struggling. This "adverse selection" of firms is only possible if the organization's rent or profits are exogenously determined by given production technology once the individuals have decided to found the organization. If profits are endogenously realized by the individuals' investments, this problem will never happen as the organization members will always adjust their investments downwards when anticipating rent seeking.

\footnotetext{
${ }^{1}$ For example, this rent can be due to saved transaction costs, secured specific investments because of vertical integration, or secured cooperation rents because of internal solutions of prisoner's-dilemma like situations.
} 
On the one hand, this adjustment guarantees that each organization member's utility strictly increases in the organization's profits. On the other hand, from a welfare perspective, adjustments may lead to more underinvestment in highly profitable organizations compared to less profitable ones. Moreover, the impact of firm size and competition on the foundation decision is discussed. The findings show that increasing firm size may or may not work against the "adverse selection" result depending on the interplay of two effects: Increasing the number of organization members implies a lower share in the organization's profits for each individual which makes foundation less attractive. However, enlarging the number of organization members discourages internal rent seeking which favors foundation. Finally, it can be shown that under competition a positive profit shock does not alter an organization member's individual utility. Hence, political interventions implying such positive shock in order to stimulate the foundation of organizations are ineffectual.

The paper is related to the work on internal rent seeking which starts with the assumption that internal relations are only covered by incomplete contracts which leave room for internal struggling. As one of the first authors, Masten (1986) builds on the rent seeking model by Tullock (1980) in order to discuss internal competition for rents. The relation of incomplete contracts and rent seeking is also directly addressed by Skaperdas (1992) and Konrad (2002). Other authors combine contest models with organization theory. Ellingsen (1997) considers a situation in which agents choose both 
productive and rent seeking efforts. He shows that in the given setting it is not optimal for the principal to eliminate rent seeking completely. Müller and Wärneryd (2001) point to the advantages of outside ownership in the presence of internal rent seeking to explain the coexistence of partnerships and stock corporations. Konrad (2004) shows that organizing distributional conflicts within a hierarchy may imply lower overall rent seeking expenditures. Inderst, Müller and Wärneryd (2005) emphasize that a large number of hierarchy levels may be beneficial for limiting overall rent seeking. Inderst, Müller and Wärneryd (2006) stress the benefits of a multi-divisional firm for reducing internal rent-seeking which can explain the replacement of the Uform with the M-form during the twentieth century. Kräkel (2006) analyzes the impact of firm size and the economic situation on the intensity of internal rent seeking. Gibbons (2005) even sketches an elemental rent seeking theory of the firm.

In the following section, the basic model is introduced. Section 3 deals with the case of exogenously given profits whereas Section 4 focuses on endogenous profits. Section 5 offers a discussion of the previous results by considering the impact of firm size and competition. Section 6 concludes. 


\section{The Basic Model}

We consider a simple two-stage game between $n$ homogeneous individuals with reservation value zero. ${ }^{2}$ At the first stage, the $n$ players have to decide on the foundation of an organization. Foundation requires capital expenditure $\kappa>0$ of each individual. Let $n$ be exogenously given (e.g. due to required human capital or limited wealth). If all $n$ players approve foundation, then the organization will realize profits $\pi>0$; otherwise the game ends since the organization is not founded, and each individual gets zero reservation value. If the organization has been founded, the $n$ organization members struggle for the distribution of $\pi$ at stage 2 . Here, each player $i(i=1, \ldots, n)$ can exert effort $e_{i}$ in order to increase his share $s_{i}$ in $\pi$. We assume a symmetric sharing function $s_{i}=s\left(e_{i} ; e_{-i}\right)$ with $e_{-i}=\left(e_{1}, \ldots, e_{i-1}, e_{i+1}, \ldots, e_{n}\right)$ $(i=1, \ldots, n)$ and $\frac{\partial s}{\partial e_{i}}>0, \frac{\partial^{2} s}{\partial e_{i}^{2}} \leq 0$ which is independent of a permutation of subscripts. Hence, the sharing function is characterized by positive but decreasing marginal returns and by symmetry among the organization members due to assumed homogeneity. Furthermore, let $s_{i} \leq 1(i=1, \ldots, n)$ and $\sum_{i=1}^{n} s_{i}=1$. We assume that effort $e_{i}$ entails costs on individual $i$, denoted by the convex function $c\left(e_{i}\right)$ with $c^{\prime}(\cdot), c^{\prime \prime}(\cdot)>0$ and $c(0)=c^{\prime}(0)=0$.

\footnotetext{
${ }^{2}$ When profits are endogenous we will have a further stage.
} 


\section{$3 \quad$ Exogenous profits}

First, let profits $\pi$ be exogenously given. At stage 2, each organization member solves

$$
\max _{e_{i}} \pi \cdot s\left(e_{i} ; e_{-i}\right)-c\left(e_{i}\right)
$$

(expenditure $\kappa$ is sunk) which leads to an interior symmetric solution $e^{*}=$ $H(\pi)$ with $H(\cdot)=h^{-1}(\cdot)$ and $h\left(e_{i}\right)=\frac{c^{\prime}\left(e_{i}\right)}{\partial s / \partial e_{i}}$ for each member $i$ with $H^{\prime}(\cdot)>$ 0 . At stage 1 , the $n$ players have to decide on foundation of the organization. Note that $s_{i}=s\left(e^{*}, \ldots, e^{*}\right)$ is identical for each player so that, in case of foundation, each player's utility can be written as

$$
u_{i}=\frac{\pi}{n}-c(H(\pi))-\kappa
$$

We obtain the following result:

Proposition 1 There exist feasible functions $s\left(e_{i} ; e_{-i}\right)$ and $c\left(e_{i}\right)$, profits $\pi_{2}>\pi_{1}$ and parameter values of $\kappa$ so that an organization with profits $\pi_{1}$ is founded but not an organization with profits $\pi_{2}$. In particular, if $c^{\prime}(H(\pi)) H^{\prime}(\pi)$ is monotonically increasing in $\pi$, there will exist three cutoff values $\check{\pi}, \tilde{\pi}$ and $\hat{\pi}$ with $\check{\pi}<\tilde{\pi}<\hat{\pi}$ so that an organization will be founded if and only if $\pi \in(\check{\pi}, \hat{\pi})$; organization members suffer from increasing profits as long as $\pi \in(\tilde{\pi}, \hat{\pi})$.

Proof. Let $c^{\prime}(H(\pi)) H^{\prime}(\pi)$ be monotonically increasing. Differentiating (1) with respect to $\pi$ yields $\frac{1}{n}-c^{\prime}(H(\pi)) H^{\prime}(\pi)$ which is positive for $\pi=0$ 
and monotonically decreasing in $\pi$. Define $\check{\pi}, \tilde{\pi}$ and $\hat{\pi}$ as $\frac{\check{\pi}}{n}=c(H(\check{\pi}))+\kappa$, $\frac{1}{n}=c^{\prime}(H(\tilde{\pi})) H^{\prime}(\tilde{\pi})$ with $\frac{\tilde{\pi}}{n}-c(H(\tilde{\pi}))-\kappa>0$, and $\frac{\hat{\pi}}{n}=c(H(\hat{\pi}))+\kappa$, with $\check{\pi}<\hat{\pi}$, which proves the second part of the proposition.

In order to prove the first part, we show that the second part holds for a specific cost and a specific sharing function which satisfy the assumptions of Section 2. Let $n=2$ and $c\left(e_{i}\right)=\frac{c}{2} e_{i}^{2}$ with $c>0(i=1,2)$. Furthermore, let $s\left(e_{i} ; e_{-i}\right)$ be a probit-form contest success function (Dixit 1987, 893). More specifically, let $i$ 's share $s_{i}=s\left(e_{i} ; e_{-i}\right)$ be determined by relative effort $e_{i}-e_{j}$ and exogenous luck $\varepsilon$ following a uniform distribution over the interval $[-\bar{\varepsilon}, \bar{\varepsilon}]$ so that $s_{i}=\operatorname{prob}\left\{\varepsilon<e_{i}-e_{j}\right\}=\frac{e_{i}-e_{j}+\bar{\varepsilon}}{2 \bar{\varepsilon}} .3$ This specification yields $\pi \cdot s\left(e_{i} ; e_{-i}\right)-c\left(e_{i}\right)=\pi \frac{e_{i}-e_{j}+\bar{\varepsilon}}{2 \bar{\varepsilon}}-\frac{c}{2} e_{i}^{2}$ and, therefore, optimal effort choices $e^{*}=H(\pi)=\frac{\pi}{2 c \bar{\varepsilon}}$ which results into strict concave utility $u_{i}=\frac{\pi}{2}-\frac{\pi^{2}}{8 c \bar{\varepsilon}^{2}}-\kappa$ for the first stage with $c^{\prime}(H(\pi)) H^{\prime}(\pi)=\frac{\pi}{4 c c^{2}}$.

The proposition shows that not always the most profitable organizations will be founded. On the contrary, it is possible that, given two alternative technologies, the organization with the less profitable technology is founded but individuals do not approve foundation of the organization with the more profitable technology because of escalating internal rent seeking at the second stage of the game. We can differentiate between four intervals. Very low

\footnotetext{
${ }^{3}$ More generally, we can assume that $i$ 's rent seeking performance is described by $q_{i}=$ $e_{i}+\varepsilon_{i}$ and that of $j$ by $q_{j}=e_{j}+\varepsilon_{j}$ with $\varepsilon_{i}$ and $\varepsilon_{j}$ being i.i.d.. If now $i$ 's share is determined by relative performance $q_{i}-q_{j}$ so that $s_{i}=G\left(e_{i}-e_{j}\right)$ with $G(\cdot)$ denoting the cdf of $\varepsilon_{j}-\varepsilon_{i}$ we will obtain a symmetric pure-strategy equilibrium $e^{*}=\pi g(0) / c$ which yields utility $u_{i}=\frac{\pi}{2}-\frac{\pi^{2}[g(0)]^{2}}{2 c}-\kappa$ being strictly concave in $\pi$. However, note that $G(\cdot)$ is not necessarily concave. Hence, we have to assume a sufficiently high impact of relative noise $\varepsilon_{j}-\varepsilon_{i}$ for the existence of a pure-strategy equilibrium.
} 
profits $\pi \in[0, \check{\pi}]$ cannot compensate an individual for his initial investment $\kappa$ and anticipated rent seeking costs so that the organization is not founded. For low profits $\pi \in(\check{\pi}, \tilde{\pi})$, the organization is founded and organization members benefit from a marginal increase in profits since the utility increasing profit effect dominates internal rent seeking. For intermediate values of $\pi$ (i.e. $\pi \in(\tilde{\pi}, \hat{\pi}))$, the players still agree to found an organization but they suffer from a marginal increase in $\pi$, because the rent seeking effect dominates the profit effect. For large values of $\pi$ with $\pi \geq \hat{\pi}$ excessive internal rent seeking prevents foundation of the organization.

To sum up, if an organization's profits are mainly determined by exogenously given technology, it is not true that, from an evolutionary perspective, only the most profitable organizations will emerge whereas less profitable organizations will not be founded. On the contrary, if internal relations are mainly covered by incomplete contracts which leave scope for internal rent seeking there may be an "adverse selection" of technologies in the sense of Proposition 1.

\section{Endogenous profits}

In this section, we assume that, in stage 1, when founding an organization each member $i$ can endogenously spend monetary resources $\mu_{i}$ to increase gross profits $\pi$. Let $\pi=\alpha \cdot y\left(\sum_{i=1}^{n} \mu_{i}\right)$ denote endogenous gross profits with $y^{\prime}(\cdot)>0, y^{\prime \prime}(\cdot) \leq 0$ and let $\alpha>0$ indicate productivity and, hence, 
profitability of the organization's applied technology. Now player $i$ 's utility at stage 1 in case of foundation is given by the concave function

$$
u_{i}\left(\mu_{i}\right)=\frac{\alpha y\left(\sum_{i=1}^{n} \mu_{i}\right)}{n}-c\left(H\left(\alpha y\left(\sum_{i=1}^{n} \mu_{i}\right)\right)\right)-\mu_{i}-\kappa
$$

An interior solution for optimal resource expenditures $\mu_{i}$ is described by first-order condition

$$
\alpha y^{\prime}\left(\sum_{i=1}^{n} \mu_{i}\right)\left(\frac{1}{n}-c^{\prime}(H(\pi)) H^{\prime}(\pi)\right)=1
$$

Let $\mu_{i}^{*}(\alpha)$ denote the solution of equation (3). By differentiating $u_{i}\left(\mu_{i}^{*}(\alpha)\right)$ with respect to $\alpha$ and applying the envelope theorem we obtain

$$
\frac{d u_{i}}{d \alpha}=\frac{\partial u_{i}}{\partial \alpha}=y\left(\sum_{i=1}^{n} \mu_{i}^{*}(\alpha)\right) \underbrace{\left(\frac{1}{n}-c^{\prime}(H(\pi)) H^{\prime}(\pi)\right)}_{=: \Omega}
$$

which is positive since $\Omega>0$ as we know from (3):

Proposition 2 Let $\pi=\alpha y\left(\sum_{i=1}^{n} \mu_{i}\right)$ describe endogenous profits with $\alpha>0$ and $\mu_{i}$ denoting monetary expenditures chosen by organization member $i$. Given an interior solution for expenditures, if an organization with technology $\bar{\alpha}$ is founded, then the same will apply to any other organization with technology $\alpha>\bar{\alpha}$.

The findings of Proposition 2 demonstrate that the "adverse selection" result of Proposition 1 will no longer hold, if profits are determined en- 
dogenously by the organization members' investments. In this situation, organizations with highly productive technologies will no longer suffer from excessive rent seeking. The players anticipate internal rent seeking in stage 2 when choosing expenditures $\mu_{i}$ at stage 1 . Hence, they will always optimally adapt their investment levels $\mu_{i}^{*}(\alpha)$ given a certain technology $\alpha$ so that productivity gains can be secured.

Of course, organization members will never choose first-best or efficient investment levels, i.e. investments that maximize welfare ${ }^{4}$

$$
W=\alpha y\left(\sum_{i=1}^{n} \mu_{i}\right)-\sum_{i=1}^{n} \mu_{i}
$$

as each member only gets the fraction $1 / n$ of realized gross profits when spending resources $\mu_{i}$ which results into the well-known free-rider problem. Let $M:=\sum_{i=1}^{n} \mu_{i}$ denote aggregate investment. Then efficient aggregate investment is characterized by ${ }^{5}$

$$
\alpha y^{\prime}(M)=1
$$

Hence, the higher the productivity parameter $\alpha$ the higher should be aggregate investment $M$ due to the concavity of $y(\cdot)$. This implies that the organization with the highest $\alpha$ should also have the highest aggregate in-

\footnotetext{
${ }^{4}$ Welfare maximization under first-best conditions which allow the use of forcing contracts leads to $e_{i}=0, \forall i$.

${ }^{5}$ Since investment costs are linear, only aggregate investment is unique and we have a continuum of equilibria at the first stage.
} 
vestment level. However, as the following result will show this correlation does not always hold if there is internal rent seeking:

Proposition 3 In the two-stage model with endogenous profits and internal rent seeking, the organizations with the most productive technologies do not necessarily have the highest level of aggregate investment.

Proof. Implicit differentiation of (3) yields

$$
\frac{\partial \mu_{i}^{*}}{\partial \alpha}=\frac{y^{\prime}(M)\left\{\Omega-\alpha y(M)\left(c^{\prime \prime}(H(\pi))\left[H^{\prime}(\pi)\right]^{2}+c^{\prime}(H(\pi)) H^{\prime \prime}(\pi)\right)\right\}}{-\alpha y^{\prime \prime}(M) \Omega+\alpha^{2}\left[y^{\prime}(M)\right]^{2}\left(c^{\prime \prime}(H(\pi))\left[H^{\prime}(\pi)\right]^{2}+c^{\prime}(H(\pi)) H^{\prime \prime}(\pi)\right)},
$$

with $\pi, \Omega$ and $M$ as being defined above. Note that the denominator is always positive, but the numerator may be either positive or negative. It will be negative, if

$$
\Omega<\alpha y(M)\left(c^{\prime \prime}(H(\pi))\left[H^{\prime}(\pi)\right]^{2}+c^{\prime}(H(\pi)) H^{\prime \prime}(\pi)\right) .
$$

Then individual and, hence, aggregate investment will be decreasing in $\alpha$.

As an example, we can use the specifications from the proof of Proposition 1 together with the parameterized production function $\pi=\alpha \sqrt{\sum_{i=1}^{n} \mu_{i}}(n=$ 2). At the second stage, player $i$ maximizes

$$
\alpha \sqrt{\mu_{i}+\mu_{j}} \cdot s\left(e_{i} ; e_{-i}\right)-c\left(e_{i}\right)=\alpha \sqrt{\mu_{i}+\mu_{j}} \frac{e_{i}-e_{j}+\bar{\varepsilon}}{2 \bar{\varepsilon}}-\frac{c}{2} e_{i}^{2}
$$


which leads to

$$
e^{*}=\frac{\alpha \sqrt{\mu_{i}+\mu_{j}}}{2 c \bar{\varepsilon}} .
$$

At stage 1, each player $i$ decides on his optimal investment level. He maximizes his strictly concave objective function

$$
u_{i}=\frac{\alpha \sqrt{\mu_{i}+\mu_{j}}}{2}-\frac{\alpha^{2}\left(\mu_{i}+\mu_{j}\right)}{8 c \bar{\varepsilon}^{2}}-\kappa-\mu_{i} .
$$

The first-order condition leads to optimal aggregate investment $\mu_{i}^{*}+\mu_{j}^{*}=$ $M=\left(\frac{2 \alpha c \bar{\varepsilon}^{2}}{\alpha^{2}+8 c \bar{\varepsilon}^{2}}\right)^{2}$.

Corollary 1 Let $c\left(e_{i}\right)=\frac{c}{2} e_{i}^{2}(c>0), s_{i}=\frac{e_{i}-e_{j}+\bar{\varepsilon}}{2 \bar{\varepsilon}}(\bar{\varepsilon}>0)$ and $\pi=$ $\alpha \sqrt{\sum_{i=1}^{n} \mu_{i}}(\alpha>0)$ with $n=2$. We have $\frac{\partial M}{\partial \alpha}>(<) 0$ if $\alpha<(>) \sqrt{8 c \bar{\varepsilon}^{2}}$.

The corollary shows that aggregate investment, $M$, increases for small values of the productivity parameter, but decreases for large ones. On the one hand, enlargement of $\alpha$ makes resource expenditures $\mu_{i}$ more productive which leads to higher investment. Note that free riding lessens increased investment incentives. On the other hand, both higher values of $\alpha$ and more investment leads to increased rent-seeking (see equation (7)) and, therefore, rent seeking costs, $c\left(e_{i}\right)$. Since $c\left(e_{i}\right)$ is a convex function, the last effect will become dominant if $\alpha$ takes on sufficiently large values. Simple comparative statics show that the lower the cost parameter $c$ and the risk parameter $\bar{\varepsilon}$, the more important will be the last effect. Of course if, on the contrary, both parameters are arbitrarily large, exerting rent seeking effort will be very 
costly and quite ineffective so that overall rent seeking incentives and, hence, the last effect will diminish.

To sum up, adjusting optimal investment to a given value of the productivity parameter $\alpha$ while anticipating rent seeking assures that organization members always gain from higher profits (Proposition 2). However, these adjustments may lead to more underinvestment at stage $1 .{ }^{6}$ As Proposition 3 shows, this effect can lead to more productive organizations investing less than less productive organizations.

\section{Discussion}

Organizations typically differ in many respects. In particular, organizations are of different size and are in different competitive environments. In order to test the robustness of the previous findings, this section considers the influence of firm size and competition on the possible "adverse selection" of organizations.

\subsection{Firm Size}

First, the interrelation between organization or firm size $n$ and the foundation of the organization will be discussed. According to the basic model, each individual has to spend starting capital $\kappa$ when founding the organization. Hence, overall starting capital amounts to $n \kappa=K$. There exist good rea-

\footnotetext{
${ }^{6}$ Recall that we have already underinvestment due to free riding.
} 
sons to think about a variation of $n$. For example, if the founder members are restricted in wealth so that individuals cannot finance $\kappa$, the number of organization members, $n$, has to be increased to achieve $K$. In the following, the implication of an increase in $n$ will be analyzed.

Let profits $\pi$ be exogenously given and foundation be efficient in the sense of $\pi>K$. Since equilibrium rent seeking in stage 2 depends on both profits and firm size, it can be written as

$$
e^{*}=H(\pi, n) \text {. }
$$

An organization member's objective function at stage 1 of the game can now be described by

$$
u_{i}=\frac{\pi-K}{n}-c(H(\pi, n))
$$

Differentiating $u_{i}$ with respect to $n$ yields the following corollary: ${ }^{7}$

Corollary 2 Let profits $\pi$ be exogenously given. An organization member's individual utility will increase (decrease) in firm size iff

$$
-c^{\prime}(H(\pi, n)) \cdot \frac{\partial H}{\partial n}>(<) \frac{\pi-K}{n^{2}} .
$$

The term on the right-hand side of (8) is always positive as foundation is assumed to be efficient. The effect associated with this term can be labeled sharing effect. If net profits, $\pi-K$, have to be shared among a larger

\footnotetext{
${ }^{7}$ Although $n$ is a positive integer, for simplicity $n$ is treated as a continuous variable.
} 
number of individuals, foundation will become less attractive. The algebraic sign of the left-hand side of (8) may be positive or negative. However, in most standard rent seeking contests it will be positive due to $\partial H / \partial n<0$. Consider, for example, a logit-form contest (see, e.g., Dixit 1987, and the axiomatization by Skaperdas 1996) with contest success function

$$
s_{i}=s\left(e_{i} ; e_{-i}\right)=\frac{f\left(e_{i}\right)}{f\left(e_{i}\right)+\sum_{j \neq i} f\left(e_{j}\right)}
$$

with $f(\cdot)$ as positive increasing and concave function. At the second stage, player $i$ maximizes

$$
\pi \frac{f\left(e_{i}\right)}{f\left(e_{i}\right)+\sum_{j \neq i} f\left(e_{j}\right)}-c\left(e_{i}\right)
$$

which is strictly concave. The first-order condition leads to

$$
\frac{\pi}{\left(\sum_{j=1}^{n} f\left(e_{j}\right)\right)^{2}}=\frac{c^{\prime}\left(e_{i}\right)}{f^{\prime}\left(e_{i}\right) \sum_{j \neq i} f\left(e_{j}\right)}
$$

By inspection of the first-order condition of another organization member $k \neq i$,

$$
\frac{\pi}{\left(\sum_{j=1}^{n} f\left(e_{j}\right)\right)^{2}}=\frac{c^{\prime}\left(e_{k}\right)}{f^{\prime}\left(e_{k}\right) \sum_{j \neq k} f\left(e_{j}\right)}
$$

we obtain

$$
\frac{c^{\prime}\left(e_{i}\right) \sum_{j \neq k} f\left(e_{j}\right)}{f^{\prime}\left(e_{i}\right)}=\frac{c^{\prime}\left(e_{k}\right) \sum_{j \neq i} f\left(e_{j}\right)}{f^{\prime}\left(e_{k}\right)} .
$$

Since each side describes the same monotonically increasing function, we have 
a symmetric equilibrium in which each player exerts

$$
e^{*}=H\left(\frac{(n-1) \pi}{n^{2}}\right)
$$

with $H(\cdot)$ being the inverse of $h\left(e^{*}\right)=\frac{c^{\prime}\left(e^{*}\right) f\left(e^{*}\right)}{f^{\prime}\left(e^{*}\right)}$ and monotonically increasing. We obtain

$$
\frac{\partial H}{\partial n}=-H^{\prime}\left(\frac{(n-1) \pi}{n^{2}}\right) \pi \frac{n-2}{n^{2}}<0 .
$$

The effect associated with $\partial H / \partial n<0$ in (8) can be called discouraging effect: The larger the number of opponents in the rent seeking contest at stage 2 , the lower will be the relative impact of individual effort and, therefore, individual effort incentives. Contrary to the sharing effect, the discouraging effect favors the foundation of large organizations because of reduced individual rent seeking.

To summarize, if the discouraging effect dominates the sharing effect large organizations are more likely to be founded than small organizations, but if the sharing effect is dominant the opposite will hold. Note that in any case of non-foundation we have a kind of adverse result since founding an organization is always efficient by assumption. Moreover, in case of a dominant sharing effect we may have the curious outcome that foundation of a small organization is impossible due to restricted wealth, but foundation of a large organization is also not possible because an individual's share in net profits, 
$(\pi-K) / n$, is too low for covering individual rent seeking costs, $c(H(\pi, n))$.

Finally, we can have a look at the case of endogenous profits as discussed in Section 4. Let again $\pi=\alpha y\left(\sum_{i=1}^{n} \mu_{i}\right)$ describe endogenous profits with $\alpha>0$ and $\mu_{i}$ as monetary expenditures chosen by organization member $i$. Now consider the case of a symmetric equilibrium, in which each organization member chooses expenditures $\mu^{*}(n)$ in stage 1 . Furthermore, let us assume that rent seeking at stage 2 follows the logit-form contest success function as introduced above (see equation (9)). Player $i$ 's objective function at stage 1 can then be written as

$$
u_{i}=\frac{\alpha y\left(n \mu^{*}(n)\right)-K}{n}-c\left(H\left(\frac{(n-1)}{n^{2}} \alpha y\left(n \mu^{*}(n)\right)\right)\right) .
$$

If we now vary firm size in the sense of $d u_{i} / d n$, again the envelope theorem will apply: $\frac{d u_{i}}{d n}=\frac{\partial u_{i}}{\partial \mu^{*}} \mu^{* \prime}(n)+\frac{\partial u_{i}}{\partial n}=\frac{\partial u_{i}}{\partial n}$. Compared to the case of exogenous profits, the only difference then results from increasing total expenditures, $n \mu^{*}$. As we can see from equation (10), this effect would work against both the sharing effect (since the numerator of the first term increases in $n \mu^{*}$ ) and the discouraging effect (since the argument of the $H(\cdot)$ function in the second term increases in $\left.n \mu^{*}\right)$. Altogether, with endogenous profits we would have the same two effects as in the case of exogenous profits but results would be less clear because of the additional effect. 


\subsection{Competition}

Up to now, we have considered a situation in which the organization can decide in isolation without paying attention to any other organization or firm which operates in the same product market. In case of a monopoly, this modelling would be correct. However, typically firms face some competition. Hence, in this subsection we consider a competitive situation with $m$ homogeneous organizations or firms. At stage 1, the firms simultaneously choose their market actions (given foundation). At stage 2, internal rent seeking takes place. Let $\pi_{f}=\alpha \cdot \pi\left(x_{f} ; x_{-f}\right)$ be the profits of firm $f(f=1, \ldots, m)$ with $\alpha>0, x_{f}$ denoting the decision of firm $f$ and $x_{-f}=\left(x_{1}, \ldots, x_{f-1}, x_{f+1}, \ldots, x_{m}\right)$ the decisions of the $m-1$ other firms, ${ }^{8}$ and $\pi$ being concave in $x_{f}$. Furthermore, let $e^{*}=H\left(\alpha \pi\left(x_{f} ; x_{-f}\right)\right)$ describe the symmetric equilibrium effort of each individual in each firm at stage 2 with $H(\cdot)$ again being a monotonically increasing function as in Section 3. Then, in stage 1 , the utility of member $i$ of firm $f$ can be written as

$$
u_{i f}=\frac{\alpha \pi\left(x_{f} ; x_{-f}\right)}{n}-c\left(H\left(\alpha \pi\left(x_{f} ; x_{-f}\right)\right)\right)-\kappa
$$

If each firm maximizes the utility $u_{i f}$ of a representative member and an interior solution exists, this solution can be characterized by the following

\footnotetext{
$f$.

${ }^{8}$ For example, in case of Cournot competition, $x_{f}$ would be the quantity chosen by firm
} 
first-order condition:

$$
\alpha \frac{\partial \pi}{\partial x_{f}} \cdot\left(\frac{1}{n}-c^{\prime}\left(H\left(\alpha \pi\left(x_{f} ; x_{-f}\right)\right)\right) H^{\prime}\left(\alpha \pi\left(x_{f} ; x_{-f}\right)\right)\right)=0
$$

Assume that - because of homogeneity - equation (11) has a symmetric solution $x^{*}(\alpha)$, and that - as in Proposition $1-c^{\prime}(H(\cdot)) H^{\prime}(\cdot)$ is monotonically increasing. In this case, firm $f$ would not implement maximum profits being characterized by $\frac{\partial \pi}{\partial x_{f}}=0$, but smaller profits so that the expression in parentheses in (11) is zero, i.e.

$$
\frac{1}{n}=c^{\prime}\left(H\left(\alpha \pi\left(\xi^{*}(\alpha)\right)\right)\right) H^{\prime}\left(\alpha \pi\left(\xi^{*}(\alpha)\right)\right)
$$

with $\xi^{*}(\alpha):=\left(x^{*}(\alpha), \ldots, x^{*}(\alpha)\right)$.

To test the "adverse selection" problem under competition, we now have to check whether

$$
u_{i f}=\frac{\alpha \pi\left(\xi^{*}(\alpha)\right)}{n}-c\left(H\left(\alpha \pi\left(\xi^{*}(\alpha)\right)\right)\right)-\kappa
$$

increases or decreases in $\alpha$. By applying the envelope theorem we obtain

$$
\frac{d u_{i f}}{d \alpha}=\frac{\partial u_{i f}}{\partial \alpha}=\pi\left(\xi^{*}(\alpha)\right)\left(\frac{1}{n}-c^{\prime}\left(H\left(\alpha \pi\left(\xi^{*}(\alpha)\right)\right)\right) H^{\prime}\left(\alpha \pi\left(\xi^{*}(\alpha)\right)\right)\right) .
$$


Since the expression in parentheses is zero according to (12), we have

$$
\frac{d u_{i f}}{d \alpha}=0
$$

In words, if in equilibrium the profitability parameter $\alpha$ increases, individual utility will remain unchanged. Hence, if an organization is not founded in the initial situation the individual players will not revise their decisions in case of an exogenous increase of firm profitability. In particular, if foundation is efficient because equilibrium profits exceed overall starting capital but the organization is not founded due to anticipated excessive rent seeking, political intervention which results into higher $\alpha$ cannot achieve efficiency.

Comparing the findings of this subsection with the result of Proposition 2 shows that the outcomes significantly differ although in both cases profits are endogenous and profit enlargement is modelled via a marginal increase of the scaling factor $\alpha$. Moreover, in both cases an increase of $\alpha$ leads to downward adjustment of the input variable $\mu_{i}$ or $x_{f}$ at the first stage, respectively, due to anticipated rent seeking at the second stage. Hence, it seems puzzling why organization members strictly benefit from increased profitability $\alpha$ in Proposition 2 but in the competition case individual utility remains unchanged. An explanation can be given by comparing the objective functions (2) and (13). In the case of equation (2), organization members directly benefit from downward adjustment of resource expenditures $\mu_{i}$ because individual input costs are reduced. However, in the case of equation (13) there is no individual cost 
reduction. Here the organization $f$ acts as a collective decision maker and chooses its input variable $x_{f}$ solely in order to implement those profits which maximize the concave objective function (13).

\section{Conclusion}

Generating non-negative profits is a necessary condition for the existence of firms. However, the results of this paper have shown that this condition is not a sufficient one since firm members do not want to maximize overall profits but their individual utilities resulting from profit and rent seeking. As rent seeking behavior strictly increases in firm's profits it may be possible that firms which would be efficient without rent seeking are not founded because individuals anticipate excessive rent seeking at the next stage. Hence, from an evolutionary perspective perhaps those organizations will survive which are not the most profitable ones but which are most successful in solving problems of internal rent seeking. The paper also shows that the theory of rent-seeking contests offers an appropriate tool-box for analyzing internal frictions such as politicking, haggling and influence activities which can be summarized as internal rent seeking. If the organization members are able to choose the degree of incompleteness of internal contracting there will be a trade-off between contracting costs (e.g. for allocating internal property rights) and the costs of rent seeking, and hence a possible starting point for a formal approach to discuss transactions costs and the theory of the firm. 


\section{References}

Arrow, K.J. (1969): The organization of economic activity: issues pertinent to the choice of market versus nonmarket allocation, Joint Economic Committee, United States Congress (Ed.): The Analysis and Evaluation of Public Expenditures: The PPB System, Vol. 1, 47-63.

Arrow, K.J. (1985): The potentials and limits of the market in resource allocation, Feiwel, G.R. (Ed.): Issues in Contemporary Microeconomics and Welfare, 107-124.

Dixit, A. (1987): Strategic behavior in contests, American Economic Review $77,891-898$.

Ellingsen, T. (1997): Efficiency wages and X-inefficiencies, Scandinavian Journal of Economics 99, 581-596.

Furubotn, E.G. and R. Richter (2005): Institutions 6 Economic Theory, 2. ed., ann Arbor: University of Michigan Press.

Gibbons, R. (2005): Four formal(izable) theories of the firm?, Journal of Economic Behavior and Organization 58, 200-245.

Inderst, R., Müller, H.M. and K. Wärneryd (2005): Influence costs and hierarchy, Economics of Governance 6, 177-197.

Inderst, R., Müller, H.M. and K. Wärneryd (2006): Distributional conflict in organizations, European Economic Review (forthcoming). 
Konrad, K.A. (2002): Investment in the absence of property rights; the role of incumbency advantages, European Economic Review 46, 1521-1537.

Konrad, K.A. (2004): Bidding in hierarchies, European Economic Review $48,1301-1308$.

Kräkel, M. (2006): Firm size, economic situation and influence activities, Discussion Paper, University of Bonn.

Masten, S. (1986): Institutional choice and the organization of production: the make-or-buy decision, Journal of Institutional and Theoretical Economics 142, 493-509.

Milgrom, P.R. (1988): Employment contracts, influences activities, and efficient oganization design, Journal of Political Economy 96, 42-60.

Milgrom, P.R. and J. Roberts (1988): An economic approach to influence acrivities in organizations, American Journal of Sociology 94, Supplement, S-154-S-179.

Müller, H.M. and K. Wärneryd (2001): Inside versus outside ownership: a political theory of the firm, RAND Journal of Economics 32, 527-541.

Skaperdas, S. (1992): Cooperation, conflict, and power in the absence of property rights, American Economic Review 82, 720-739.

Skaperdas, S. (1996): Contest success functions, Economic Theory 7, 283290. 
Tullock, G. (1980): Efficient rent seeking, Buchanan, J.M., R.D. Tollison, and G. Tullock, Eds., Toward a theory of the rent-seeking society, College Station, 97-112. 